\title{
The spatio-temporal NDVI analysis for two different Australian catchments
}

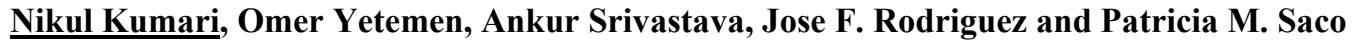 \\ School of Engineering, Faculty of Engineering and Built Environment, The University of Newcastle, \\ Callaghan, NSW 2308, Australia. \\ Email: Nikul.Kumari@uon.edu.au
}

\begin{abstract}
Contrasts in insolation lead to the development of aspect-controlled ecosystems characterized by heterogeneity in vegetation type and density in semi-arid ecosystems. The aspect-controlled solar radiation creates variation in the type and amount of vegetation across the two opposite facings of the hillslopes. In the Southern Hemisphere (SH), the north-facing slopes (NFS) have an abundance of paleotropical xeric biota, whereas the south-facing slopes (SFS) have higher densities of mesic temperate species. The reverse patterns are mostly observed in the Northern Hemisphere (NH). In the SH, SFS are dominated by the evergreen sclerophyllous woodland, while open scrub vegetation with spiny shrubs, sub-shrubs, and small trees exist on the NFS. This general vegetation pattern creates differences in erosion control and resistance on different slopes, and thus the underlying landscapes evolve differently. Although many previous studies have focused on aspect-controlled vegetation growth in the $\mathrm{NH}$, there have been limited studies in the $\mathrm{SH}$, especially in Australia.

Remote sensing provides one of the best options to capture the long-term biomass changes over the large spatial and temporal coverage. The normalized difference vegetation index (NDVI) is based on the relationship between the reflectance of the red and near-infrared bands of multispectral sensors, and it can be used due to its computational simplicity and easy accessibility. In this study, we considered two catchments, Mount Wilson, South Australia and Risdon Hills in Tasmania to study the long-term spatial and temporal variation in NDVI at these catchments. Both sites are unaffected or minimally affected from anthropogenic activities upon visual inspection through Google Earth ${ }^{\mathrm{TM}}$, in addition to reviewing both sites from the literature. We also explored how the precipitation and potential evapotranspiration patterns at these sites affect the vegetation growth during the year.
\end{abstract}

In this study, we extracted NDVI values derived from Landsat 5, 7, and 8 (obtained from Google Earth Engine) for a 18-year period (2000-2017) for both catchments. Thereafter, we used 30-m SRTM DEM to calculate the aspect and slope datasets for two locations. With the aspect data classified, the vegetation index NDVI is computed for each slope, NSF and SFS. We compared and contrasted the inter-annual variability in NDVI at the two sites to capture the temporal variation in NDVI. We have also introduced $N D V I_{\text {diff }}$ as the difference between NDVI at NFS to SFS, where $N D V I_{\text {diff }}>0$ states that NDVI is higher on NFS than SFS and vice-versa. The spatial NDVI is extracted for the summer and winter months, November and June, respectively, to see the seasonal NDVI at each catchment.

The results show that the Mount Wilson site $\left(\sim 35^{\circ} \mathrm{S}\right)$ has higher NDVI values than the Risdon Hill site throughout the year though receiving similar annual precipitation. It is observed that the Mount Wilson site shows approximately similar NDVI on NFS and SFS in the austral summer period. However, in the winter season when seasonal total precipitation exceeds total PET demand, the NDVI on NFS is comparatively higher than on SFS, which is attributed to differences in vegetation phenology on opposing hillslopes and relatively more incoming solar radiation on NFS than SFS. On the other hand, the site at Risdon Hills $\left(\sim 42^{\circ} \mathrm{S}\right)$ has relatively lower range of NDVI at both NFS and SFS, and NDVI at NFS and SFS does not vary noticeably. Further, the spatial NDVI patterns at both locations also illustrate similar behaviour, following the temporal patterns at both locations.

Keywords: NDVI, remote sensing, aspect, insolation 


\section{INTRODUCTION}

In semiarid regions, variation in the solar insolation has a profound impact on the topography via the feedback mechanism among the hydrology, vegetation, sediment transport, and landscape evolution (Yetemen et al., 2015). The global insolation is significantly higher at the equator than at higher latitudes like $60^{\circ} \mathrm{N}$ or $60^{\circ} \mathrm{S}$ (Bras 1990). The annual mean extra-terrestrial radiation maximizes at the equator $\left(\sim 400 \mathrm{~W} / \mathrm{m}^{2}\right)$, and it reduces to minimal at poles $\left(\sim 300 \mathrm{~W} / \mathrm{m}^{2}\right)$. It has been demonstrated in various studies that the amount of insolation on equatorward-facing slopes to poleward-facing slopes increases at higher latitudes (Yetemen et al., 2015; Zhou et al., 2013). Further, the seasonal variability in mean extra-terrestrial radiation is minimal at the equator with a range of 380 and $430 \mathrm{~W} / \mathrm{m}^{2}$; and this variability increases with latitude approximately between 110 and 510 $\mathrm{W} / \mathrm{m}^{2}$. The gradient and aspect orientation control the solar energy incident on landscapes, which in turn controls local water balance and biomass production. Thus solar insolation plays a crucial role across the opposing hillslopes by creating a different environment on opposite hillslopes in terms of water availability, plant type, and density.

The differences in the amount of insolation create differences in available soil moisture on opposing hillslopes and thus has a direct impact on the vegetation type and density (Gutiérrez-Jurado et al., 2006; Stenberg and Shoshany, 2001). The Southern Hemisphere (SH) has south-facing slopes (SFS) that are cooler, moister, and more densely vegetated with higher evapotranspiration rates, and north-facing slopes (NFS) that are warmer and drier with more frequent and larger runoff magnitudes (Armesto and Martínez, 1978; Kirkpatrick and Nunez 1980). The opposite occurs in the Northern Hemisphere (NH) (Sternberg and Shoshany, 2001; Gutiérrez-Jurado et al., 2006; Hinckley et al., 2014). The aspect-related variations in insolation affects the soil moisture on opposing slopes, leading to vegetation heterogeneity on opposing hillslopes. Generally, denser and mesic biomass (like an evergreen sclerophyllous woodland) is dominant on south aspects while north aspects are occupied by sparser and xeric plants (like open scrub vegetation with spiny shrubs, sub-shrubs, and small trees) in the SH, while the opposite patterns are followed in the NH. The existence of abundant biomass on SFS (NFS) upholds the soil more tightly, which leads to developing relatively more erosion resistant surface that increases the infiltration capacity and minimizes the overland flow. In turn, sparser vegetation density in the NFS (SFS) of the SH (NH) leads to more channel formations and a more dissected topography prone to higher erosion (Armesto and Martínez, 1978; Gutiérrez-Jurado et al., 2006).

It is necessary to study the vegetation patterns at spatial and temporal scales as vegetation plays a vital role in creating differences across the opposing hillslopes by providing different resisting forces on the erosion mechanism and runoff protection. Since it is challenging to quantify biomass on opposing hillslopes, remote sensing is a better way to capture the long term spatial and temporal pattern of vegetation in any given area. The normalized difference vegetation index (NDVI) is used as the proxy for quantifying the biomass differences. NDVI is based on the relationship between the reflectance of the red and near-infrared bands of multispectral sensors. It has been used to monitor the degree of desertification, status, and health of crops, global warming, and changes in land-cover and land-use in addition to biomass production. The NDVI is based on the observation that vegetated and non-vegetated surfaces have different albedo characteristics (Stensrud 2007). This index is mostly used because of its computational simplicity, and it can be easily accessible for any required location. The NDVI has a fixed range of values falling between -1 and 1 , where the values greater than zero are considered for the vegetation.

In this study, our primary focus is to understand the spatial and temporal behaviour of NDVI using remote sensing data for Australian sites. We considered two locations having similar mean annual precipitation but different seasonality, one from South Australia (Mount Wilson site) and other from Tasmania (Risdon Hill site) which are unaffected or minimally affected from anthropogenic activities. The main objective of this study is to capture the seasonal patterns of NVDI at these two different catchments in Australia. Further, it also focuses on the respective precipitation and potential evapotranspiration patterns of the catchments, which may be responsible for these seasonal NDVI patterns. Hence, we have also used LANDSAT NDVI dataset, along with the precipitation and PET data analysis present in this study.

Section 2 provides a brief description of the NDVI theory and the equations involved in NDVI calculation; followed by Section 3 showing the study area site descriptions. Section 4 describes the methodology briefly followed by Section 5 and 6, which show the results and discussion with the conclusion, respectively. 


\section{THE STUDY SITE DESCRIPTION}

Figure 1 shows the sites located at Mount Wilson and Risdon Hills. The site at Mount Wilson is located in the Mount Lofty Ranges of South Australia located approximately at $138.6^{\circ} \mathrm{E}$ and $35.21^{\circ} \mathrm{S}$ and $370 \mathrm{~m}$ above sea level. The long-term mean annual precipitation and temperature are approximately $760 \mathrm{~mm}$ and $15^{\circ} \mathrm{C}$, respectively. The relief and mean slope for this site are $210 \mathrm{~m}$ and $16^{\circ}$, respectively. This site is generally characterized by cold and wet winters and hot and dry summers resembling Mediterranean climate. The other site is located in Risdon Hills, located approximately at $147.2^{\circ} \mathrm{E}$ and $42.78^{\circ} \mathrm{S}$ and $350 \mathrm{~m}$ above sea level. The long-term mean annual precipitation and temperature are $750 \mathrm{~mm}$ and $12^{\circ} \mathrm{C}$, respectively. This site has a mild temperate climate and is humid throughout the year. The relief and mean slope for this site are $320 \mathrm{~m}$ and $12^{\circ}$, respectively.

The Mount Wilson site generally has tall evergreen trees on the SFS while deciduous shrub or small trees dominate the NFS (Xu et al., 2017). The Risdon Hills vegetation varies from Southern blue gum, evergreen trees to Eucalyptus without a clear pattern (Kirkpatrick and Nunez 1980). Both locations are not affected by anthropogenic activities, and we confirmed this by a visual inspection via Google Earth ${ }^{\mathrm{TM}}$, and from reviewing both sites from the literature. Although both locations have similar mean annual precipitation, the rainfall pattern varies throughout the seasons (described in section 5.3). These two sites are used to study the temporal variation in NDVI across north-facing and south-facing slopes as well as to understand the inter-annual NDVI variability.

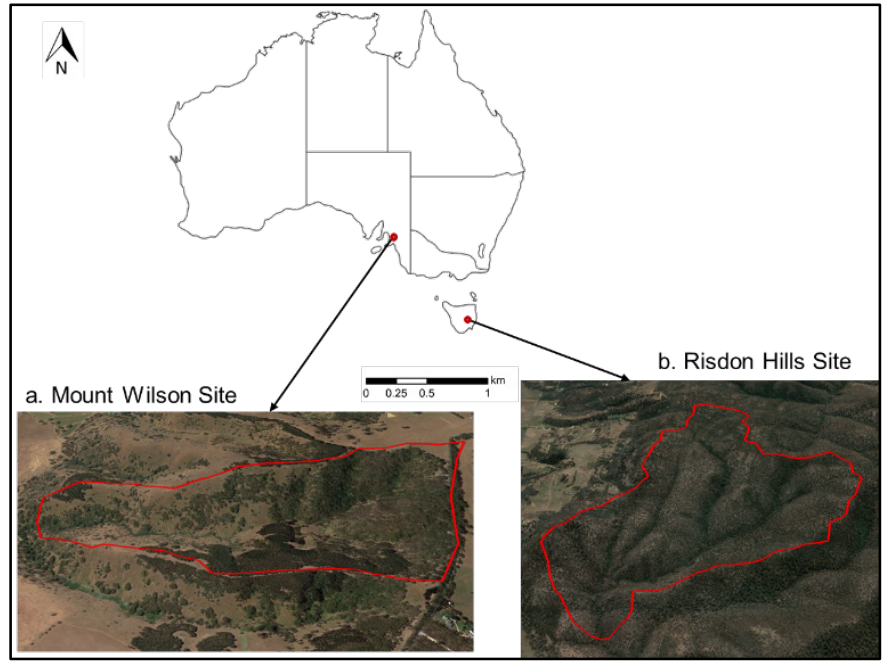

Figure 1. The sites considered in this study

\section{METHODOLOGY}

\subsection{Data used}

In this study, we used the 32-day NDVI composite data from Landsat 5, 7, and 8 that are computed from topof-atmosphere (TOA) reflectance using Google Earth Engine (GEE); for the last 18-year period of 2000-2017. GEE is a cloud-based platform that makes it easy to access high-performance computing resources for processing very large geospatial datasets (Gorelick et al., 2017). We extracted the monthly precipitation data for the required locations using the WorldClim 2 (http://worldclim.org) at $\sim 1 \mathrm{~km}^{2}$ - spatial resolution (Fick and Hijmans, 2017). Further, in order to obtain the potential evapotranspiration (PET) data for the required site, we followed Zomer et al., 2008. 30-m resolution digital elevation models (DEMs) were taken from the United States Geological Survey (USGS) (http://www.usgs.gov/) for the topographic analysis of the two catchments.

\subsection{Method of Analysis}

The DEMs are re-projected to their particular Universal Transverse Mercator (UTM) coordinate system using ArcMap 10.3. A huge number of voids were present in the topography, hence prior to the pre-processing, we filled the internal sinks to maintain connected flow paths up to the outlet of the catchment. The simplest method, D8 (eight flow directions) in which flow is assigned to every pixel towards the steepest downward slope is used to procure the aspect, slope, and flow directions datasets for the various locations. Four cardinal quadrants, each of $90^{\circ}$ width are used for binning the aspect datasets such that, north falls between 0 to $45^{\circ}$ and $315^{\circ}$ to $360^{\circ}$; south $135^{\circ}$ to $225^{\circ}$; east and west are categorized between $45^{\circ}$ to $135^{\circ}$ and $225^{\circ}$ to $315^{\circ}$, respectively. Once, the aspect for both the catchments is obtained, we segregated the NDVI of each catchment according to the north-facing and south-facing slopes. Further, we compared and contrasted the inter-annual variability in NDVI at the two sites to capture any existing trend. The precipitation and PET monthly patterns are also studied to understand the vegetation growth at the two locations. Further, the spatial NDVI is extracted for the summer and winter months, November and June respectively to evaluate the seasonal NDVI at each of the sites. We have introduced $N D V I_{\text {diff }}$ as the difference between NDVI at NFS to SFS, where $N D V I_{\text {diff }}>0$ states that NDVI is higher on NFS than SFS and vice-versa conditions. 


\section{RESULTS}

\subsection{Temporal NDVI pattern at Mount Wilson and Risdon Hill Sites}

Figure 2 shows the mean NDVI at NFS and SFS for the twelve months averaged over the last 18-year period at the Mount Wilson site and the Risdon Hill site. The NDVI ranges from 0.10 to 0.42 at the former site while NDVI lies between 0.10 and 0.22 at the Risdon Hill site. It is observed that the Mount Wilson site $\left(35^{\circ} \mathrm{S}\right)$ shows approximately similar NDVI on NFS and SFS in the austral summer period. However, in October and November, the NDVI on SFS is comparatively higher than NFS (NDVI diff $\sim 0.01)$, and winter season shows a seasonal change in the NDVI pattern. It is observed that the NDVI is higher at NFS than SFS in May-June, which shows that winter precipitation favours more vegetation. On the other hand, the site at Risdon Hills $\left(42^{\circ} \mathrm{S}\right)$ have a comparatively lower range of NDVI at both NFS and SFS in comparison to the Mount Wilson Site. Further, the NDVI at NFS and SFS do not vary noticeably at Risdon Hill site. The long-term mean NDVI values at NFS and SFS at both sites show different pattern throughout the year.

Table 1 shows the long-term mean, maximum, minimum, and the standard deviation values of NDVI for NFS and SFS for both sites. It is observed that the NDVI is always higher at Mount Wilson site as compared to that of Risdon Hill location. The maximum NDVI at NFS is 0.6752 and at SFS is 0.6608 ; while the minimum NDVI falls to be 0.03 (NFS) and 0.025 (SFS) at Mount Wilson location. At Risdon Hills, the maximum and minimum NDVI values are 0.59 (NFS) and 0.01 (SFS), respectively. The standard deviation values (Table 1) show more variability of NDVI values on the NFS than in the SFS locations that could be associated with the higher dispersion and scarcity of vegetation in the SFS slopes, dominated by lower and smaller scrubs that do not cover the entirety of soil.

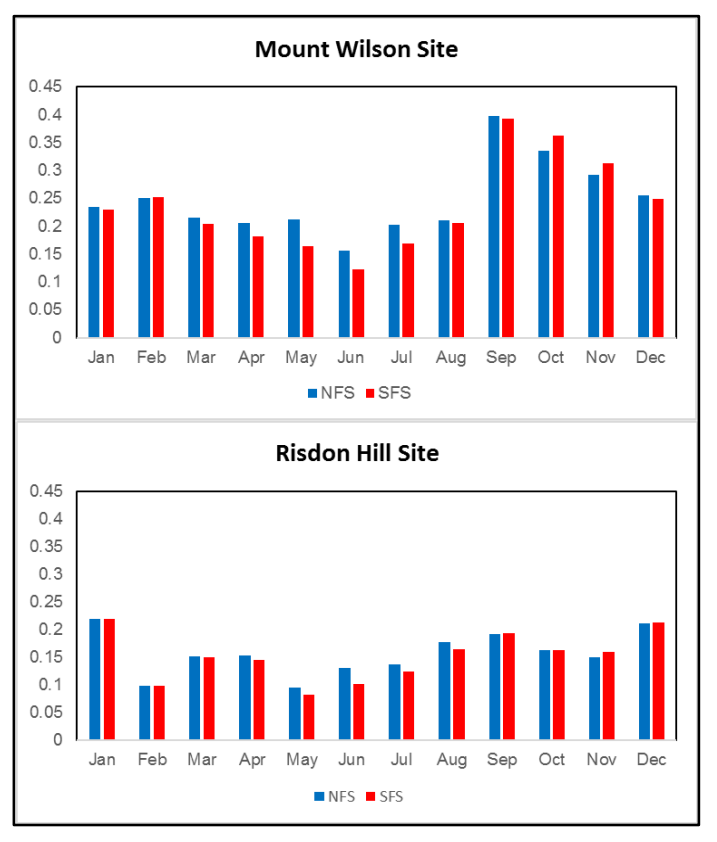

Figure 2. NDVI at NFS and SFS at both sites

Figure 3 shows the interannual $N D V I_{\text {diff }}$ of NDVI for 18 years (2000-2017) at both catchments. The $N D V I_{\text {diff }}$ varies from 0.22 to -0.25 at the Mount Wilson site. It is observed that the Mount Wilson site has a varied pattern of NDVI throughout the years. In most of the summer months, the NDVI is higher at SFS that NFS. As $N D V I_{\text {diff }}$ is negative whereas during the winter periods (May-June), the $N D V I_{\text {diff }}$ is always positive inferring that NFS holds higher vegetation than SFS. However, the NDVI differences at NFS and SFS do not varied much at the Risdon Hill site as compared to the Mount Wilson Site. The $N D V I_{\text {diff }}$ varies from 0.12 to -0.1 at the Risdon Hill site. At this site, the $N D V I_{\text {diff }}$ is higher in winter with the maximum in June (1.2) and lower in the summer months with a minimum in August (-0.1). The winter season showed a wider range in comparison to summer.

Table 1. Temporal NDVI analysis at NFS and SFS

\begin{tabular}{|l|r|r|r|r|}
\hline & \multicolumn{2}{|c|}{ Mount Wilson } & \multicolumn{2}{c|}{ Risdon Hill } \\
\cline { 2 - 5 } & NFS & \multicolumn{1}{|c|}{ SFS } & \multicolumn{1}{c|}{ NFS } & \multicolumn{1}{l|}{ SFS } \\
\hline Mean & 0.26 & 0.25 & 0.16 & 0.16 \\
Maximum & 0.68 & 0.66 & 0.59 & 0.58 \\
Minimum & 0.03 & 0.02 & 0.02 & 0.01 \\
Std dev & 0.23 & 0.22 & 0.19 & 0.18 \\
\hline
\end{tabular}

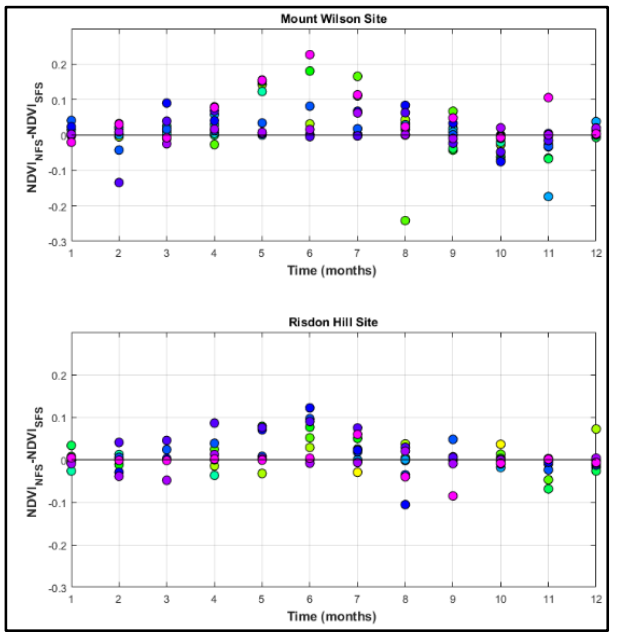

Figure 3. Inter-annual $N D V I_{\text {diff }}$ at both the sites sites 


\subsection{Spatial NDVI pattern at Mount Wilson and Risdon Hill Site}

Figure 4 shows the coefficient of variation (CV) of NDVI across the two locations for all seasons. The CV of NDVI at Risdon Hills is comparatively higher than the Mount Wilson site. The Mount Wilson site has 233 SFS pixels and 195 NFS pixels while the Risdon Hill site has 1100 SFS pixels and 650 NFS pixels. This number of pixels is big enough to carry out the aspect wise NDVI analysis over the catchment. At the Mount Wilson site, the $\mathrm{CV}$ is generally higher and more variable in the winter season (1.4 is maximum), with lower and more uniform values in the summer season. However, the variability in NDVI at Risdon Hill maximizes early winter and decreases until the end of winter, and stays fairly constant during the spring and summer.

Figure 5 shows the mean spatial NDVI at the Mount Wilson site averaged over 18 years for the summer (November) and winter (June) month. The NDVI ranges from 0.16 to 0.41 in the winter while NDVI lies between 0.24 and 0.55 in the summer. It is observed that the Mount Wilson site shows approximately similar NDVI on NFS and SFS in austral summer period over the entire catchment. However, during the winter period, the NFS has comparatively higher NDVI as compared to the SFS of the catchment. It is observed that in winter $(0.41)$ the overall NDVI is comparatively lower than the summertime (0.55) in November. This may be attributed to denser or higher vegetation at NFS during winter as compared to the SFS in summer

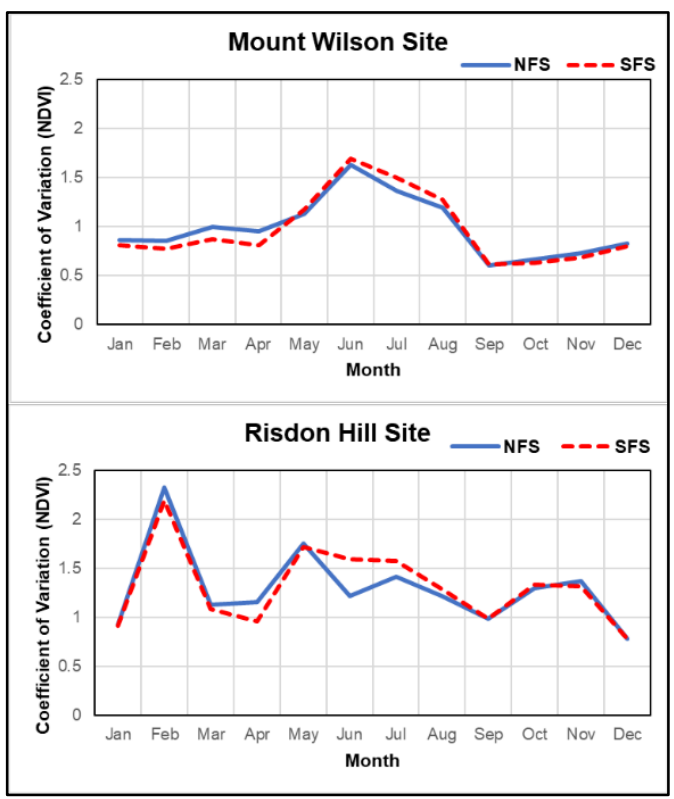

Figure 4. The CV of NDVI at both the Sites

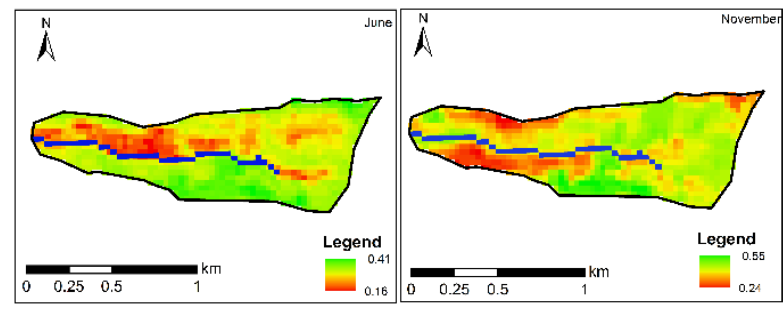

Figure 5. NDVI at Mount Wilson site

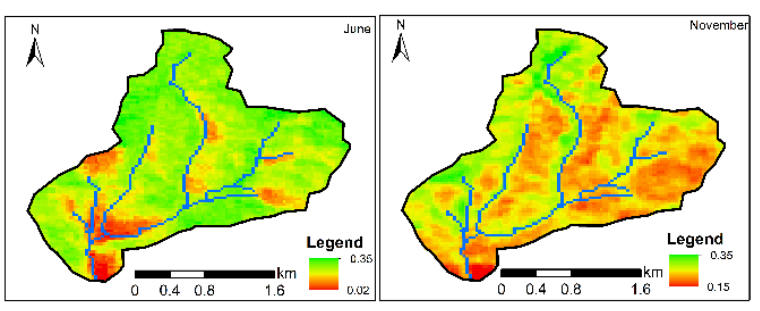

Figure 6. NDVI at Risdon Hill site

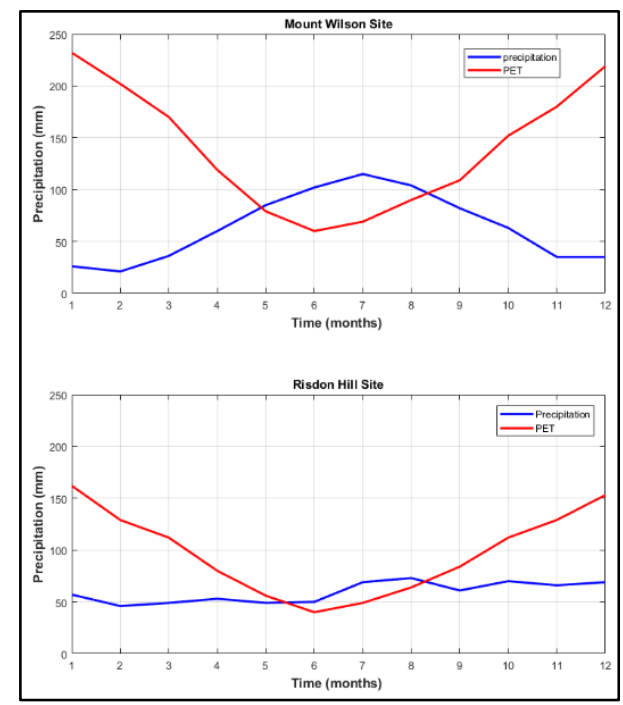

Figure 7. Precipitation and PET at Mount Wilson and Risdon Hills 
It is observed that the Mount Wilson site has higher precipitation during winter time while the other site has uniform precipitation throughout the year. Also, the PET comparatively higher at the former site, ranging from $235 \mathrm{~mm}$ (summer) to $80 \mathrm{~mm}$ (winter); and it varies from $155 \mathrm{~mm}$ to $45 \mathrm{~mm}$ at the latter site. This shows the seasonal transition from the water-limited region in summer to the energy-limited condition in the winter season. Thus, we observed lesser NDVI at SFS than NFS during the winter season, where the rainfall along with the required sunlight conserves the vegetation growth more efficiently. The winter precipitation enhances more vegetation at Mount Wilson site due to the sufficient requirement of soil moisture as well as solar radiation.

\section{DISCUSSION AND CONCLUSION}

The main focus of this study is on the spatio-temporal NDVI patterns across the opposing hillslopes in Australia. Generally, SFS have higher vegetation than NFS in the SH (Armesto and Martinez, 1978) and higher vegetation on NFS than SFS in the NH (Hinckley et al., 2014). However, most of the observations made in the previous studies are carried out in the NH and mostly in summer, with a very limited focus in the SH. In order to capture the temporal and spatial NDVI analysis, satellite data usage becomes very helpful, which has been carried out in this study. Here, we conducted spatial and temporal NDVI analysis for two catchments at two different locations in Australia, Mount Wilson site, and Risdon Hill site.

In this analysis, we showed the considerable seasonal reversal in NDVI across the opposing hillslopes at the Mount Wilson site while very little differences at the Risdon Hill site. The time series of the normalized NDVI values for the NFS and SFS is presented (Figure 2) for both the sites; the variation from higher values of NDVI at the Mount Wilson site to lower values of NDVI at the Risdon Hill site is illustrated. It is observed that the vegetation index for the NFS shows higher values during winter time in comparison to the SFS during the summer at Mount Wilson site. With respect to the average NDVI on SFS, the value for the Mount Wilson site was 0.245 , while for the Risdon Hill site it reduced to 0.15 (Table 1). This is because the evaporative demand at the Risdon Hill site is greater than the available moisture for the vegetation practically throughout the hydrological year. Further, the spatial NDVI patterns at both the locations also illustrate similar behaviour as shown in the temporal patterns at both locations (Figure 4).

Overall, it is observed that despite the similar mean annual precipitation at both the sites, the NDVI patterns vary both spatially and temporally. This may be due to the difference in the rainfall pattern, with the Mount Wilson Site receiving 75 percent of its total rainfall in winter season and the Risdon Hill site presenting a uniform precipitation pattern. Further, the vegetation types may be another reason for this behaviour at opposing hillslopes. The large increase in NDVI during spring may indicate fast growth of grass and pasture at the Mount Wilson site (Xu et al., 2017). On the other hand, the Risdon Hill site have more established forest resulting in comparitively little variations in NDVI. This suggests that the SFS better retain the soil moisture, and the vegetation takes an advantage of the circumstances during the precipitation in the winter time. It also suggests that there may exist higher retention time for the soil moisture at SFS as there is a lower rate of evaporation resulting from shorter sun exposure (less solar radiation), in contrast to NFS.

\section{REFERENCES}

Armesto, J. J., and Martínez, J. A. (1978). Relations between vegetation structure and slope aspect in the Mediterranean region of Chile. The Journal of Ecology, 881-889.

Bras, R. L. (1990). Groundwater flow in saturated porous media. Hydrology, an introduction to hydrologic science, 283-312.

Fick, S. E., \& Hijmans, R. J. (2017). WorldClim 2: new 1-km spatial resolution climate surfaces for global land areas. International journal of climatology, 37(12), 4302-4315.

Gutiérrez-Jurado, H. A., Vivoni, E. R., Harrison, J. B. J., and Guan, H. (2006). Ecohydrology of root zone water fluxes and soil development in complex semiarid rangelands. Hydrological Processes, 20(15), 32893316.

Gorelick, N., Hancher, M., Dixon, M., Ilyushchenko, S., Thau, D., \& Moore, R. (2017). Google Earth Engine: Planetary-scale geospatial analysis for everyone. Remote Sensing of Environment, 202, 18-27. 
Hinckley, E.-L. S., Ebel, B. A., Barnes, R. T., Anderson, R. S., Williams, M. W., and Anderson, S. P. (2014). Aspect control of water movement on hillslopes near the rain-snow transition of the Colorado Front Range. Hydrological Processes, 28(1), 74-85.

Kirkpatrick, J. B., \& Nunez, M. (1980). Vegetation-radiation relationships in mountainous terrain: eucalyptdominated vegetation in the Risdon Hills, Tasmania. Journal of Biogeography, 197-208.

Sternberg, M., and Shoshany, M. (2001). Influence of slope aspect on Mediterranean woody formations: comparison of a semiarid and an arid site in Israel. Ecological Research, 16(2), 335-345.

Stensrud, D. J. (2007), Parameterization Schemes: Keys to Understanding Numerical Weather Prediction Models, Cambridge Univ. Press, New York.

Xu, X., Guan, H., Skrzypek, G., \& Simmons, C. T. (2017). Response of leaf stable carbon isotope composition to temporal and spatial variabilities of aridity index on two opposite hillslopes in a native vegetated catchment. Journal of Hydrology, 553, 214-223.

Yetemen, O., E. Istanbulluoglu, A.R. Duvall (2015), Solar radiation as a global driver of hillslope asymmetry: insights from an ecogeomorphic landscape evolution model. Water Resour. Res., 51: 9843-9861.

Zhou, X., E. Istanbulluoglu, and E. R. Vivoni (2013), Modeling the ecohydrological role of aspect-controlled radiation on tree-grass-shrub coexistence in a semiarid climate, Water Resour Res, 49(5), 2872-2895.

Zomer, R. J., Trabucco, A., Bossio, D. A., and Verchot, L. V. (2008). Climate change mitigation: A spatial analysis of global land suitability for clean development mechanism afforestation and reforestation. Agriculture, Ecosystems and Environment, 126(1-2), 67-80. 